\title{
FOXP2 gene and language development: the molecular substrate of the gestural-origin theory of speech?
}

\author{
Carmelo M. Vicario* \\ School of Psychology, The University of Queensland, Brisbane, QLD, Australia \\ *Correspondence: uqcvicar@uq.edu.au
}

Edited by:

Kuniyoshi L. Sakai, The University of Tokyo, Japan

The view that language evolved from a primarily gestural mode of communication has its roots on the 18th-century philosophers speculations (Vico, 1953/1744; de Condillac, 1971/1756).

Over time, these philosophical thoughts have gradually got consistence, thanks to the research in the field of Psychology and Neuroscience, which has provided exciting evidence in support of the so-called gestural origin-theory of language (Corballis, 2002). This theory recognizes to the gestures a precise role in language development. In particular, in terms of evolution it has been suggested that spoken language evolves from an ancient communication system using arm gestures. Accordingly, it has been suggested that gestures of the mouth might have been added to the manual system to form a combined manuofacial gestural system (Corballis, 2002; Gentilucci and Corbalis, 2006).

The literature on Mirror Neurons has provided a strong support to the gesturalorigin theory thanks to the evidence of a close relationship between arm (Gallese et al., 1996; Rizzolatti et al., 1996) and mouth actions (Ferrari et al., 2003) in the brain of non-human primates. In particular, it has been shown that the area F5 of the monkey premotor cortex includes also a class of neurons that discharge when the animal grasps an object with the either the hand or the mouth (Rizzolatti et al., 1988). However, although a recent meta-analysis of 125 human fMRI studies (Molenberghs et al., 2012) identified a core network of human brain regions that possess mirror properties associated with action observation and execution, there is also a literature that challenges the existence of these neurons in humans. In fact, direct evidence for the existence of mirror neurons in humans is still lacking (Dinstein et al., 2008; Hickok, 2009). On the other hand, some studies provide data against it. For example, the study of Lingnau et al. (2009) failed in finding adaptation for motor acts that were first executed and then observed (as found for executed motor acts, when these were preceded by execution or observation of the same motor act) in the brain areas that are typically considered as endowed of mirror properties. This implies that the link between motor gestures and spoken language is not necessarily mediated by neurons provided of "mirror" properties.

Clues in support of the gestural-origins theory of the language are also provided by the research on humans. For example, grasping larger objects (Gentilucci et al., 2001) and bringing them to the mouth (Gentilucci et al., 2004) induces selective increases in parameters of lip kinematics and voice spectra of syllables pronounced simultaneously with action execution. Moreover, it has been reported that repetitive transcranial magnetic stimulation of Broca's area affects verbal responses to gesture observation (Gentilucci et al., 2006). This suggests that Broca's area is probably involved in the simultaneous control of gestures and word pronunciation.

Neuroimaging studies on humans provide a further support to this direct link between gestures and verbal language. Sakai et al. (2005) used functional Magnetic Resonance Imaging to examine hemispheric dominance during the processing of signed and spoken sentences. Their study was provided of two conditions: (i) the sign condition with sentence stimuli in Japanese Sign Language (JSL) in which were tested Deaf signers of JSL, hearing bilinguals (children of Deaf adults, CODA) of JSL and Japanese (JPN); (ii) the speech condition in which were tested hearing monolinguals (Mono) of JPN with auditory JPN stimuli alone (AUD), or with an audiovisual presentation of JPN and JSL stimuli (A and V). The authors found that the ventral part of the left inferior frontal gyrus $(\mathrm{F} 3 \mathrm{t} / \mathrm{F} 3 \mathrm{O})$ showed no main effects of modality condition, providing evidence in support of the existence on a common area for the processing of linguistic information from both signed and spoken sentences. Moreover, it has been recently documented the common involvement of the left area $7 \mathrm{~A}$ in the superior parietal lobule while performing a sequenced button presses task or a sequence of different syllables repetition task (Heim et al., 2012). These data demonstrate the existence of a common cortical module in the area 7A while sequencing vocal gestures and hand motor actions.

Finally, a support to the gestural-origin theory of language originates from the study of human infants. For example, Fogel and Hannan (1985) provided evidence of gesture-vocalization synchrony in 2-and 3-months-old human infants. Word comprehension in children between 8 and 10 months and word productions between 11 and 13 months are typically accompanied by deictic gestures (Volterra et al., 1979; Bates and Snyder, 1987). Deictic gestures (referring to an object or location) are particularly important since they allow reference to grow from the immediate context toward abstraction by helping infants understand the link between symbols and referents (De Villiers Rader and Zukow-Goldring, 2010). Moreover, deictic gestures seem able to predict linguistic development in both typical and atypical human populations across many cultures (Iverson and Goldin-Meadow, 2005). All these studies suggest that gestures provide a foundation for each new stage in early linguistic development.

A recent discovery in the field of genetics seems providing new insights in support of the gestural-origin theory. 
In particular, evidence suggests that the FOXP2 gene, located on the human chromosome 7 (Fisher et al., 1998), could be the molecular substrate linking speech with gesture. In fact, this gene is involved not only in speech production and comprehension but also in gesture coordination.

In an early work Gopnik (1990) argued that the FOXP2 gene is involved in the development of morphosyntax. For this motivation this gene has been identified more broadly as the "grammar gene" (Pinker, 1994). However, a subsequent investigation suggested that the core deficit associated with the abnormal expression of this gene is one of articulation, with grammatical impairment as secondary outcome (Watkins et al., 2002). Thus, it was proposed (Corballis, 2004) that this gene may play a role in the incorporation of vocal articulation, but have little to do with grammar itself. In support of this suggestion it has been reported that FOXP2 shows overlapping expression patterns within brains of zebra finches and fetal human brains, particularly in subcortical regions that play important roles in sensorimotor integration and coordinated movements important for vocalization and speech (Teramitsu et al., 2004). Moreover, recent studies on humans extend the role of FOXP2 gene to the coordination of upper limb movements. For example, the recent study of Peter et al. (2011) found an influence of the FOXP2 gene on several language processing tasks such as nonword repetition, real word reading efficiency, rapid oral reading. Interestingly, they documented an effect of this gene also on rapid motor sequencing ability which also included finger movements.

Another recent work (Wilcke et al., 2012) has shown that the Single Nucleus Polymorphism (rs12533005) of the FOXP2 gene can be associated with congenital dyslexia. Interestingly, the difficulty with sequential finger movements is another type of deficit which may characterize reading disorders (Tiffin-Richards et al., 2004). Furthermore, FOXP2 mutations seem to account for the childhood apraxia of speech (CAS) (MacDermot et al., 2005; Laffin et al., 2012), which is characterized by problems in saying sounds, syllables, and words. Peter (2012) recently described the CAS FOXP2 phenotype in multi-generational families as characterized not only by deficits in sequential processing at the level of alternating oral motor movements, which is consistent with the traditional CAS definition as a motor programing disorder, but also by deficits in sequential hand movements.

All these studies provide suggestive evidence that the FOXP2 gene might be the possible molecular substrate linking gestures with verbal language. However, the research in support of this hypothesis is still limited, although there are promising fields of investigation. For example, it would be interesting to assess the impact of the FOXP2 gene polymorphism on linguistic and manual skills in healthy adults. This investigation not only would provide a further support to the molecular substrate hypothesis for the gestural-origin theory of speech, but it could have also practical implications for developmental and educational psychology, as it might allow an early assessment of the risk for dyslexia and/or dysgraphia in childhood individuals.

Other potential issues worthy of investigation might refer to the study of the expression of FOXP2 in individuals with special linguistic and/or manual skills (e.g., polyglot people, painters of talent); the influence played by particular socio-environmental factors on its expression, which in turn might influence linguistic and/or manual skills of healthy individuals.

Finally, it would be intriguing to valuate whether the FOXP2 genetic variations influence the resilience of linguistic and/or manual functions in patients affected by stroke.

\section{REFERENCES}

Bates, E., and Snyder, L. S. (1987). "The cognitive hypothesis in language development," in Infant Performance and Experience: New Findings with the Ordinal Scales, eds E. Ina, C. Uzgiris, and E. J. McVicker Hunt (Urbana, IL: University of Illinois Press), 168-204.

Corballis, M. C. (2002). From Hand to Mouth: The Origins of Language. Princeton, NJ: Princeton University Press.

Corballis, M. C. (2004). FOXP2 and the mirror system. Trends Cogn. Sci. 8, 95-96. doi: 10.1016/j.tics.2004.01.007

de Condillac, E. B. (1971/1756). An Essay on the Origin of Human Knowledge: Being a Supplement to Mr.
Locke's Essay on the Human Understanding (A facsimile reproduction of the 1756 translation by $T$. Nugent of Condillac's 1747 essay). Gainesville, FL: Scholars' Facsimiles and Reprints.

De Villiers Rader, N., and Zukow-Goldring, P. (2010). How the hands control attention during early word learning. Gesture 10, 202-221. doi: 10.1075/gest.10.2-3.05rad

Dinstein, I., Thomas, C., Behrmann, M., and Heeger, D. J. (2008). A mirror up to nature. Curr. Biol. 18, R13-R18. doi: 10.1016/j.cub.2008.01.044

Ferrari, P. F., Gallese, V., Rizzolatti, G., and Fogassi, L. (2003). Mirror neurons responding to the observation of ingestive and communicative mouth actions in the monkey ventral premotor cortex. Eur. J. Neurosci. 17, 1703-1714. doi: 10.1046/j.1460-9568.2003.02601.x

Fisher, S. E., Vargha-Khadem, F., Watkins, K. E., Monaco, A. P., and Pembrey, M. E. (1998) Localisation of a gene implicated in a severe speech and language disorder. Nature Genet. 18, 168-70. doi: $10.1038 / n g 0298-168$

Fogel, A., and Hannan, T. E. (1985). Manual actions of nine- to fifteen-week-old human infants during face-to-face interaction with their mothers. Child Dev. 56, 1271-1279.

Gallese, V., Fadiga, L., Fogassi, L., and Rizzolatti, G. (1996). Action recognition in the premotor cortex. Brain 119, 593-609. doi: 10.1093/brain/119.2.593

Gentilucci, M., Benuzzi, F., Gangitano, M., and Grimaldi, S. (2001). Grasp with hand and mouth: a kinematic study on healthy subjects. J. Neurophysiol. 86, 1685-1699.

Gentilucci, M., Bernardis, P., Crisi, G., and Dalla Volta, R. (2006). Repetitive transcranial magnetic stimulation of Broca's area affects verbal responses to gesture observation. J. Cogn. Neurosci. 18, 1059-1074. doi: 10.1162/jocn.2006.18.7.1059

Gentilucci, M., and Corbalis, M. C. (2006). From manual gesture to speech: a gradual transition. Neurosci. Biobehav. Rev. 30, 949-960. doi: 10.1016/j.neubiorev.2006.02.004

Gentilucci, M., Santunione, P., Roy, A. C., and Stefanini, S. (2004). Execution and observation of bringing a fruit to the mouth affect syllable pronunciation. Eur. J. Neurosci. 19, 190-202. doi: 10.1111/j.1460-9568.2004.03104.x

Gopnik, M. (1990). Feature-blind grammar and dysphasia. Nature 344, 715. doi: 10.1038/344715a0

Heim, S., Amunts, K., Hensel, T., Grande, M., Huber, W., Binkofski, F., et al. (2012). The role of human parietal area $7 \mathrm{~A}$ as a link between sequencing in hand actions and in overt speech production. Front. Psychol. 3:534. doi: 10.3389/fpsyg.2012.00534

Hickok, G. (2009). Eight problems for the mirror neuron theory of action understanding in monkeys and humans. J. Cogn. Neurosci. 21, 1229-1243. doi: 10.1162/jocn.2009.21189

Iverson, J. M., and Goldin-Meadow, S. (2005). Gesture paves the way for language development. Psychol. Sci. 16, 367-371. doi: 10.1111/j.09567976.2005.01542.x

Laffin, J. J., Raca, G., Jackson, C. A., Strand, E. A., Jakielski, K. J., and Shriberg, L. D. (2012). Novel candidate genes and regions for childhood apraxia of speech identified by array comparative genomic hybridization. Genet. Med. 14, 928-936. doi: 10.1038 /gim.2012.72 
Lingnau, A. Gesierich, B., and Caramazza, A. (2009). Asymmetric fMRI adaptation reveals no evidence for mirror neurons in humans. Proc. Natl. Acad. Sci. U.S.A. 106, 9925-9930. doi: 10.1073/pnas.0902262106

MacDermot, K. D., Bonora, E., Sykes, N., Coupe, A. M., Lai, C. S., Vernes, S. C., et al. (2005). Identification of FOXP2 truncation as a novel cause of developmental speech and language deficits. Am. J. Hum. Genet. 76, 1074-1080. doi: 10.1086/430841

Molenberghs, P., Cunnington, R., and Mattingley, J. B. (2012). Brain regions with mirror properties: a meta-analysis of 125 human fMRI studies. Neurosci. Biobehav. Rev. 36, 341-349. doi: 10.1016/j.neubiorev.2011.07.004

Peter, B. (2012). Oral and hand movement speeds are associated with expressive language ability in children with speech sound disorder. J. Psycholinguist Res. 41, 455-474. doi: 10.1007/s10936-0129199-1

Peter, B., Raskind, W. H., Matsushita, M., Lisowski, M., Vu, T., Berninger, V. W., et al. (2011). Replication of CNTNAP2 association with nonword repetition and support for FOXP2 association with timed reading and motor activities in a dyslexia family sample. J. Neurodev. Disord. 3, 39-49. doi: 10.1007/s11689-0109065-0

Pinker, S. (1994). The Language Instinct. New York, NY: Morrow.
Rizzolatti, G., Camarda, R., Fogassi, L., Gentilucci, M., Luppino, G., and Matelli, M. (1988). Functional organization of inferior area 6 in the macaque monkey. II. Area F5 and the control of distal movements. Exp. Brain. Res. 71, 491-507. doi: 10.1007/BF00248742

Rizzolatti, G., Fadiga, L., Gallese, V., and Fogassi, L. (1996). Premotor cortex and the recognition of motor actions. Cogn. Brain. Res. 3, 131-141. doi: 10.1016/0926-6410(95)00038-0

Sakai, K. L., Tatsuno, Y., Suzuki, K., Kimura, H., and Ichida, Y. (2005). Sign and speech: amodal commonality in left hemisphere dominance for comprehension of sentences. Brain 128, 1407-1417. doi: 10.1093/brain/awh465

Teramitsu, I., Kudo, L. C., London, S. E., Geschwind, D. H., and White, S. A. (2004). Parallel FoxP1 and FoxP2 expression in songbird and human brain predicts functional interaction. J. Neurosci. 24, 3152-3163. doi: 10.1523/JNEUROSCI.558903.2004

Tiffin-Richards, M. C., Hasselhorn, M., Richards, M. L., Banaschewski, T., and Rothenberger, A. (2004). Time reproduction in finger tapping tasks by children with attention-deficit hyperactivity disorder and/or dyslexia. Dyslexia 10, 299-315. doi: $10.1002 /$ dys. 281

Vico, G. B. (1953/1744). La Scienza Nuova. Bari: Laterza.

Volterra, V., Bates, E., Benigni, L., Bretherton, I., and Camaioni, L. (1979). "First words in language and action: a qualitative look," in The Emergence of Symbols: Cognition and Communication in Infancy, eds E. Bates, L. Benigni, I. Bretherton, L. Camaioni, and V. Volterra (New York, NY: Academic Press), 141-222.

Watkins, K. E., Dronkers, N. F., and Vargha-Khadem, F. (2002). Behavioural analysis of an inherited speech and language disorder: comparison with acquired aphasia. Brain 125, 452-464. doi: 10.1093/brain/awf058

Wilcke, A., Ligges, C., Burkhardt, J., Alexander, M., Wolf, C., Quente, et al. (2012). Imaging genetics of FOXP2 in dyslexia. Eur. Hum. Genet. 20, 224-229. doi: 10.1038/ejhg.2011.160

Received: 09 July 2013; accepted: 18 July 2013; published online: 05 August 2013.

Citation: Vicario CM (2013) FOXP2 gene and language development: the molecular substrate of the gesturalorigin theory of speech? Front. Behav. Neurosci. 7:99. doi: 10.3389/fnbeh.2013.00099

Copyright (c) 2013 Vicario. This is an open-access article distributed under the terms of the Creative Commons Attribution License (CC BY). The use, distribution or reproduction in other forums is permitted, provided the original author(s) or licensor are credited and that the original publication in this journal is cited, in accordance with accepted academic practice. No use, distribution or reproduction is permitted which does not comply with these terms. 